\title{
The Catalytic effect of the Pop Up in the Otherness Process the Aesthetics for the Development of the Ethical Sense
}

\author{
José Silveira Dias $^{1}$, Maria João Neto ${ }^{2}$ \\ ${ }^{1}$ CIAUD Researcher, Faculty of Architecture, University of Lisbon, PORTUGAL \\ ${ }^{2}$ Prof. Dr. Maria João Neto, Faculty of Architecture, University of Lisbon, PORTUGAL
}

Abstract: This paper presents a reflection on the Pop Up as an object of investigation of ephemerality looking for its design, as part of a PHD investigation in Design, focused on event design.

The concept of otherness proposes that all social man interacts with and interdependent on the other. The existence of the self is only possible in contact with others. In an expanded view, he becomes the other and is reflected retroactively in society itself.

Sustained on the basis of thoughts of Arendt, Certeau, Bourriaud, Lipovetsky and Flusser, this reflection defends the Pop Up as a catalyst for otherness process which regulates the ethical sense of community, through artistic activity.

While the new, obsolescence and fashion triumph, the authentic, genuine and traditional are also develop as opposites. This paradox arises in daily life, on which the grandeur of the public sphere is concerned with being efficient and where irrelevant escapes under it. The particular enchantment or the little things - "petit bonheur" is not public, even if adopted by the whole community.

The irrelevant lies in the interstitial, as a space for human relations. This space legitimates chances of exchanges other than those of the current system, even when placed openly in the global system. The creation of open spaces generates a particular time whose rhythm contrasts everyday life and strengthens a different human relationship that is imposed by the consumer and spectacle society.

It is believed that the vacuum created by the resignation of the great revolutionary changes was replaced by the more immediate involvement of human relations, encouraging affection as a condition.

Our age witnessed clashes between value systems that defend the pluralisation and democratization of the ethical domain. Promoting the affection in the relationship with moral values and solidarity behaviours correspond to a new social form of ethical life. This affection is developed through the artistic act.

Through the Pop Up, we will be towards the value of an aesthetic model of existence additional to those proposed by the mass market, recovering the classical humanist culture, as a reaction to the of the world through artistic capitalism. The Pop Up shall be registered in the history of mankind and its different ways to make life more beautiful.

The Pop Up as a strategy of event design shelters the irrelevant in the interstitial. The Pop Up drives the individual to participative and collaborative practice, during its predefined life cycle, and through artistic activity. At the same time, through various artistic expressions (urban art, conceptual art, etc.), and outside the institutional circuit, it retroactively develops a sense of ethical responsibility.

The demonstration of artistic practices by their public display, it shows favourable for the expression of proximity, allowing narrow the space on which relationships forms evolve according to dynamics and social contexts through their possibilities and uses.

The art while socializing and mediating dialogue factor, is relational. For example, the images have the ability to promote feelings of attachment and assembly. Oriented in the production of living arrangements, art can boost and complement the modern design of the individual emancipation through art and design, offering new cultural and political direction.

The mutability of the Pop Up adapts to any territory (time and space) to be reactivate. During its life cycle, on reveal itself, it accelerates the possibilities, and, retroactively, on hide itself identifies utilities, having a catalytic effect.

Connecting knowledge and experience, the Pop Up event may stimulate creativity through individual and collective action for the humanization.

Keywords: Pop Up, Event Design, Otherness, Aesthetics, Ethical Sense 


\section{The Pop Up as a model of the Event Design}

The reflection developed in this article on the Pop Up is part of a research for a PhD in Design, focused on event design, constituting the Pop Up the research object of ephemerality in search of its design (design).

As conceptual construction, the event Pop Up defines its anticipation by lifecycle, revealing himself from a participatory practice, which is thought as a project. The catalytic effect of Pop Up aims to stimulate and encourage participation among creators and users. With the interaction of both, promotes behaviours and actions in order to establish relationships, adding value to the participants and enhancing the professed intention.

The application of the concept Pop Up is identifiable in the following situations: Pop-up book that, when opened, emerges and develops three-dimensional buildings, revealing dynamic and colourful worlds from the inside of the book; the extra "window" that opens a webpage, whose sudden appearance interrupts the user's routine and sends it to parallel worlds, extra information or advertising; Pop Up Store, a category of shop under the Retail Design, which is an appropriate strategy for marketing as charming mishap and that can transpose a brand to fantasy and glamour worlds. This reflection is developed from the situation implemented by the Retail Design.

Retail environments is always changing, provides trends and anticipate changes in response to consumer aspirations, demanding that retail spaces should be spaces constantly updated, innovative, interactive and visionary.

Pop Up Store is a temporary store that survives for a short period of time in the transportation of a brand. It has installation character and derives from guerrilla marketing (strategy that uses unconventional methods through interaction between producers and users with low economic and investment and income of the parties involved). The Pop Up Store can be mobile (outpatient) and the location and event are normally not announced. This concept serves to raise the status of the brand and allows consumers to access to exclusive products that can only be only find in this place. It also provides the consumer to participate in an interactive action, often without the presence of the product itself. For entrepreneurs or marks, the priority of this type of business is not always profit, because the Pop Up Stores are also a way to verify the acceptance of the product or service in the market. They are test labs in the territory and with the community [1].

The Pop Up Store as a category of shop used in Retail Design is characterized by dynamics of event (cause/effect), cell (mobile/portable) and stratagem (of mishap/manifest). Its evaluation as an experimental model of design (prototype) can validate its application in other areas, in addition to retail. Its virtues (transgression, contamination, portability, revelation, mishap and stratagem) may consolidate Pop Up as a model in the dynamics of consumption, culture and art.

The Pop Up conceptualization in the ephemeral strategy (revelation and concealment) as a model of the event, may also contribute to the definition of design as a catalyst of social purpose: in the recovery of the sense of community and new economic and cultural dynamics in groups, tribes and associations; in driving the recovery and revitalization of the heritage (tangible and intangible) and new forms of business in the retail consumption as well as in other areas such as culture, education, health and leisure.

The following characteristics of Pop Up are also noteworthy: its experimental character that allows you to test possibilities in the search for specific uses; its changing ability that allows you to adapt to the constraints (spatial and temporal, social and economic); its expansive possibility that its catalytic effect develops creating new perspectives to look, enjoyment and intervention in the spaces and objects. In its strategy as display it wants visitors to see what is exposed and that they have the opportunity to interact with the system allowing the return of their experience, acquiring the status of users - to move from inaction to action.

Ideally, this present contribution will be subject to registration and analysis for future retroaction as part of the investigation process.

\section{Everything depends on Intention}

When reflecting on art, Okakura [2] states that when one leaves something to say [in a work of art], the viewer gets the opportunity to complete the idea. A masterpiece holds our attention until it seemed that we have become an integral part of it. There is a vacuum that we may enter it and fill with our aesthetic emotion. When one experiences a work of art, you give yourself emotions and analogies to one particular space and time, and, in 
turn, it involves us with his aura, which incites and emancipates the perceptions and thoughts of each other. The work offers shapes and surfaces to the senses, but also incorporates physical and mental connections, giving us greater coherence and meaning to life itself, thus stimulating creativity in future retroaction.

In essence, the Design discusses the kind of life that should develop in a natural way with objects. It talks about states of mind that he seeks to encourage and sustain. To feel something as beautiful, more than just an aesthetic attribute, suggests identification with the lifestyle we want to promote with the design of this "thing". And to feel the beauty of a building (material or immaterial), also reflects the need to find a material expression of the notion we have of what is living well.

The ambition of the Design in conquering its common-place leads us to stop believing that art and technology are sources of value and to give ourselves account of the intention [design] that sustains them. As Flusser [3] refers, the intention [design] consists of deceive the nature through technical change of the natural for what is artificial and build devices capable of revealing the god that is within us and that we have created in his likeness to give us transcendence - an ex-machina god that liberates the conditioned human condition.

The intention of the designer as a producer of culture will be to transform surreptitiously the man, who is conditioned by nature, in a free artist. As event strategy, Pop Up may materialize artefacts that suddenly reveal in an unlikely way, to solve a problem or give it a conclusion. Thus, promotes the liberation (creative) of the subject with the transformation caused. Abrupt experience rips the subject of emotional submission (nourished by the media) and forces him to reflect and act to solve the problem, constituting a rational emancipation. The focus converges to the object and releases the subject for the purpose (intention).

\section{The Human Condition}

According to Arendt [4], man is a conditioned being because everything that comes in contact with it immediately becomes a condition of its existence. Things are produced by the sum of man's activities and capabilities and the existence of things is due exclusively to the production of man. Through things, man constantly creates its own conditions and these, in turn, have the same condition strength of natural things.

The impact on the everyday human existence is felt and received as a conditioning force. Human existence would be impossible without things and these would be a meaningless amalgamation (a non-world) if they were not conditions of human existence. Arendt adds that the man who may know determine and define the essence of everything that surrounds it, is not able to do the same about himself and it would be like to jump over his own shadow [4]. However, the conditions of human existence (life, birth, death and the existence of men on earth as the world's inhabitants) do not explain what we are for the simple reason that they do not affect us absolutely.

Seduced by the new, under the obsolescence and fashion regime, we are conditioned by mass capitalism, that develops into counterpoint the authentic, the genuine and the traditional. In everyday life, while efficiency is the primary concern of the public sphere, irrelevant escapes under it. What is considered irrelevant by public sphere can be adopted by an entire community infected by his charm without losing its essentially private character. For Arendt [4], the happiness of little things - "petit bonheur" - is the art to escape the domain of the public sphere where industrialization constantly dismantles created things to make new things.

Indeed, the extraordinary nature of the little things is in the public sphere inability to house the irrelevant.

According to Arendt [4] live in the world means above all to have a world of things interposed between those who live in it together. The world as an intermediary establishes a relationship that simultaneously separates and brings men together. The societal problem of massification is that the world that stands between people lost the ability to relate them to each other and dissipated competence of the meeting, of approximation and departure among men.

On the condition of a common world, the reality is not guaranteed by the common nature of all men, but by the diversity of perspectives and positions for the benefit of the same world (object). On the condition of a mass society, where people behave homogeneously, men are deprived of the meeting, to see and hear one another and to be seen and heard by others. The subjectivity of its own existence remains isolated even if that individual experience is multiplied many times. As Arendt [4] argues, seen only on one side and in a single perspective, the common world ends, because you lose the relationship as a condition to preserve. 


\section{The Relational Aesthetics}

With the proliferation of current formats of socialization (media, of fun and entertainment parks, shopping centers), we are reduced to the status of mere consumers of time and space since, according to the postulates of the capitalist economy, that which cannot be marketed tends to disappear [5].

In a world regulated by the division and specialization of labour, by automation and by profit, it is of the convenience of the capitalist system that human relations are guided by a pre-established order and in accordance with controllable and reproducible principles. The human relationship (symbolized, transformed into merchandise or marked by logos) to escape the predictable domain is forced to adopt alternative or even clandestine ways. It is noted that, in the consumer society of the masses, even the social ties have become standard products.

The artistic achievement emerges as a fertile interface for social experimentation, as a territory still preserved from the standardization of behaviours - that which Bourriaud termed a utopia of proximity [5]. The artistic activity is a game where the forms and functions evolve over time according to dynamics and social contexts and with a changeable essence. At present, the works of art do not aim to build imaginary and utopian realities, but rather modes of existence or action models within the everyday reality at an appropriate scale of the problem identified. The artistic activity is circumstantial and serves to transform the context of everyday life, to set up relationship with the sensible or conceptual world in a more lasting universe.

Modernity extends still in the practice of "do it yourself" (Levi-Strauss) and "readymade" (Duchamp), in reinvention of everyday life and in the organization of the time lived [5].

Art has always been relational as socialization factor and mediating dialogue. The image has the power to gather and promotes the feeling of connection. Signs, symbols and icons produce widespread empathy and sharing, generating bonds. Artistic practices manifested by its expository character, like the Pop Up event, appear favourable to the proximity of expression allowing narrow space relations. It sets out here the possible place for dialogue, discussion, exchange of views and travel, all in the same space-time.

In addition to its commercial nature or its semantic value, the artwork represents a social interstice expression used by Marx to describe communities exchange escaping the capitalist economic framework, for not obeying the law of profit. The interstitial space for human relationships authorizes possibilities for different exchanges existing in the capitalist system, even when placed in an open and harmonious global system forms. The creation of open spaces that create own time durations and whose rhythm contrasts with everyday life, favours a different human relationship from that imposed by the communication society.

The artists begin to question their own artistic language, the image itself, which suddenly dominates everyday life in the contemporary world. The creator works in the critical evaluation of his work (form and matter). Currently, reflect on art is much more important than the very art itself - Conceptual Art. Art is no longer the ultimate goal, but the relational object, through which one may reflect on the new content of the dayto-day, considering the acceleration caused by the immediate changes in real time.

Each individual creates their own way through their behaviour, their way of presenting and addressing others. The form emerges from this contact zone in which the individual is competing with each other to impose that which he believes to be his own existence. According Bourriard [5], the form only becomes conscious and acquires a real existence when it brings into play human interactions, as well as a work of art is born of a negotiation with the intelligible. Through it, it is establishes a dialogue. The invention of relations between subjects is the essence of artistic practice and in every artistic work is proposed to forms of cohabitation in the world.

\section{The Art of making the Everyday Life}

How an entire society cannot be reduced to the network of surveillance technologies seedlings that determine the institutional scenarios? What popular procedures (irrelevant and interstitial) do not conform to the discipline, except to change the mute processes that organize social, cultural and political? Certeau [6] questions that these "ways of doing" are creative practices by which men re-appropriate themselves time and space through the socio-cultural production procedure modes. Within the capitalist homogenized mass society, we can distinguish microsurgical operations which alter their operation through "tactical" applied on "details" of 
everyday life (interstitial and irrelevant reside in everyday life). Popular culture formulates in the art of making, promotes a way of thinking that invests in a course of action, in the art of combining, hand in hand with art to use [6].

Pop Up takes advantage of "occasions" and depends on them to draw benefits, expand knowledge and glimpse outputs. This non-place allows mobility between the adversities in search of opportunities offered by the moment. For Certeau [6], we must be aware of the breaches that the particular situations will open in the surveillance of the current capitalist system. As a stratagem, mounts an ambush for its prey and as covert conspiracy extends its pitfalls. Misused from guerrilla marketing and economics interface for social and political territory, it is presented as a playful dynamic where underlies the interaction of all participants. It interrupts the routine to praise the exceptional on an aesthetic platform through practical know-how with ethics.

The option of possibilities before certain circumstance is numerous in daily heterogeneity. The act of shopping is constituted by the entire mental process that involves this action: the management of what is necessary under the superfluous; the management of likes according to what to buy and for whom it is; the need to save combined with what we already have. That is, it is an exercise in intellectual synthesis that is so not a speech, but the decision itself, the act and the way to take the opportunity.

Will be the detail and the small pleasures, it that come with the day-to-day which could host the greatness of things.

\section{The Aesthetic Economy}

According to Lipovetsky [7], capitalism appears as an irreconcilable system with an aesthetic life, with beauty and harmony, with a good life. The liberal economy emancipates the prosaic nature of social life at the expense of his poetic. It promotes global uniformity of urban landscape through the monotony and dehumanization of similar business ventures, homogenizing human life with shopping and entertainment centers, subdivisions and condominiums, with highways, networks and tourism complexes. Not only unemployment, such as social inequalities and human dramas, so with the disharmony of life forms and the dissipation of enjoyment of social life, are symptoms diagnosed by this "proletarianization" in lifestyles, reducing the autonomy of these typologies of life at the disposal and control of capitalist production. Having at the expense of being is the "claim" of this society. The industry develops disposable, interchangeable and insignificant product. The advertising visually contaminates public space. The media foment futility, vulgar and violence, filling the brain time available and configure shelters banality of everyday life. Emotions are commercialized.

Through dehumanization of large urban concentrations, the weakening of ecosystems and sensations, which contributes to the mass of the banal, the capitalist mode of production seems to impoverish sensuousness as economic responsible for the retrogression of beauty dimension.

Wonders if the system geared by industrial revolution and that has such adverse effects in the moral, social and economic terms, it will also inevitably on the aesthetic level? How it is developed the aesthetic domain during world excrescence of the market economy?

Throughout its secular history, the logic of industrial production and culture has changed. They referred to separate, irreconcilable universes. Now, production systems, distribution and consumption are remodelled by any aesthetic operations.

The strategy of the brands imposes itself through style, beauty, taste and sensitivity. Branding becomes imperative in driving and defining the aesthetic production that defines capitalism exacerbated consumption and that Lipovetsky termed hyperconsumption [7]. In consumer industries, through its touchpoints, brands create mass products full of seduction, affection and sensitivity, implementing a fertile aesthetic universe and heterogeneous by the eclecticism of styles that develop.

If capitalism contributes to an world of excessive consumption, also gives rise to a real aesthetic economy with plenty of styles, trends, images, narratives, landscapes, shows and exhibitions, which inevitably contributes to the aesthetical everyday. The world is being built by aesthetic and emotional dimension driven by heightened competition of brands. It increases the growth of markets and the sensitivity of the design process in the systematic work of stylization of goods and commercial places, in the integration of art, visual and affection, in the consumer universe. 
According to Lipovetsky [7], the expansion of contemporary financial capitalism does not exclude the growing strength of an artistic type of capitalism, into break with the production systems of the economy based on production and mass consumption. Modern culture of quantified rationality of capitalism and economic efficiency gives increasing importance to the creative, intuitive and emotional dimensions. The new phase of modernity, the hypermodernity (Lipovetsky designation) after the age of industrial production is more reflective and emotional.

In addition, the aestheticization of the world driven by artistic capitalism, according to Lipovetsky [7], is inscribed in the history of mankind, which has always created styles and narratives in order to make life more beautiful. The market economy appropriates this dimension. In the history of art, the modern age gives a new dimension to the aesthetics of economy, creates mass art to make aesthetic life an ambition for everyone. The aesthetic capitalism creates an aesthetic economy and starts a society whose culture is based on the principles of aesthetics and develops an unprecedented aesthetic individual. The aesthetic has become an object of consumption masses and a model of democratic life.

Everyday life is remodelled by the exercise of the art, for access to the beautiful through the pleasures and emotional narratives for all, and on the other hand, by a culture that promotes the new and the old in an exacerbated consumerism. If the aesthetic life involves creating itself, then it should not be limited to encourage the maximization of consumption. The starting point for leisure complemented with playful, enjoyment to encourage experimentation and contemplation to introduce the interaction, a model like the Pop Up can speed this walk by everyday improving knowledge and harmony of existence, improving and enriching him.

Today, the aesthetic capitalism is a generator of the individual emancipation worldwide marketing of lifestyles. There being no great alternative escape to the consumerist system, it is necessary to provide alternatives to reduce excessive anxiety consumption, promote guidance and involvement in the process whose strategy (design with social intent) anticipates a life with more quality. Assuming that consumption is condition it will be desirable to the invention or strengthening of all devices enabling men enjoy more non-commercial pleasures without loss of welfare satisfaction.

Through the Pop Up, we intend to stand before the appreciation of an aesthetic model of existence beyond the models that are proposed by the mass market as well retrieving a classical humanist culture, as a reaction to the aestheticization of the world through artistic capitalism. For Lipovetsky [7] education, training and classical humanist culture are decisive and coordinated to the world as it is today and as it will be in the future. The Pop Up as social interaction model can also sign up in the history of mankind and its different ways to make life more beautiful.

\section{The Aesthetics looking for the Ethical Sense}

Since the 1990s, we have been witnessing a global and simultaneous change of society, economy, politics and culture. The world is changing and with it people, customs and desires change. From the acceleration of this change and the perception of its consequent wear - that is, the erosion that causes such a perception - can be inferred from an urgent and present need of society for pursuit of ethical and moral values. In the transition from a society of the third industrial revolution to the knowledge and information society, it is imposed the need and the desire to learn, to know more and understand the world better.

The technology as a producer of equipment expresses the state of relations of production, creates ways of thinking, living and seeing, on an upward acceleration, constant change and in real time. The informatics dominates the culture. The computer causes changes in the way we feel and handle the information. The speed with which evolve the everyday technologies also modifies the behaviours and social identity.

From a society of remaining tangible assets of an economy of material goods of industrial capitalism, where the field of means of production dictated the development and wealth, one switches now to a new knowledge society: a society with the ambition to build their own understanding of the world by recognizing and interpreting the phenomena in a more altruistic context.

Otherness as process designs that every man interacts and depends of each other. The existence of the "self" is only possible through contact with the "other" - that in an expanded vision becomes the other (the collective). The self exists only from the other, of the other view, which also allows us to understand the world from a 
different perspective, leaving both different, like ourselves, moved by the experience of reciprocal contact interaction.

The interaction establishes a mutual relationship, but conditioned between entities. The concept is designed inside of things and is conceptualized through them. It is this disposition that includes the parties in the process and from which is structured knowledge. Knowledge is only possible to the concept level. With the concept we understand the correlation between the entities involved. In this process, the concept structures times within him and conceives a narrative. The narrative appears when the beginning and the end of a process have a carrier unit and founder of sense: a narrative process with its own time (rhythm and tempo), their own space (non-place) and where the action (performance) is developed by participants. After its concealment, it is promoted the development of a future commitment retroaction.
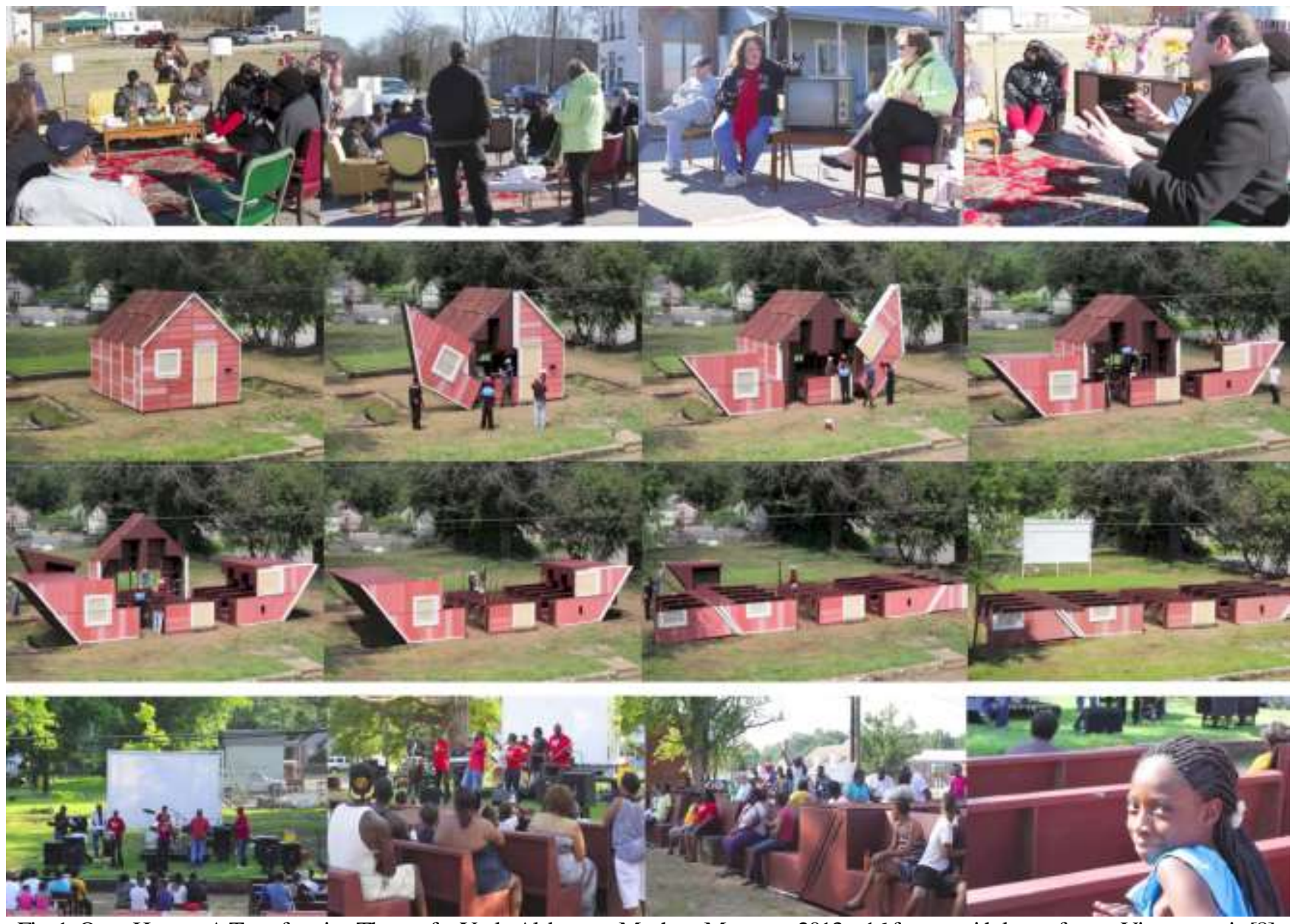

Fig. 1: Open House - A Transforming Theatre for York, Alabama - Matthew Mazzotta, 2013 - 16 frames withdrawn from a Vimeo movie [8]

The Pop Up is presented as a concept for the event of the narrative: the event that is discontinued and opens up new space-time; escapes the calculation, the prediction and conjecture; grants to the state before an entirely new state. The Pop Up as a category of event has the pretext to find in its place anything that was missing in the previous state. In the discontinuity caused by his appearance establishes the experience. The transformation brought about by the experience rips the subject of emotional submission, promoting their rational emancipation, granting them autonomy and freedom through future retroaction after his disappearance.

The excitement is short lived and addict as an expression of subjectivity, while the experience requires permanence, reflection and contemplation as an expression of objectivity (rationality). The consumer economy promotes meanings and emotions as means of production and commodity, rather than to the use value, to increase productivity and performance. Contradicting the aesthetic capitalism that sets emotional models to maximize consumption, it is intended through the Pop Up to defend an experimental model that encourages, develops and preserves feelings that allow a narrative articulation, an appointment with yourself and others by 
understanding intuition and perception. It requires individual responsibility and, in correlation with each other, has repercussions in the collective responsibility - as intention, on condition, in the relationship, in everyday life and in the current economic context - to develop an aesth[ethics].

\section{Acknowledgements}

This research was financially supported by the Research Centre for Architecture, Urbanism and Design (CIAUD) at the Faculty of Architecture, University of Lisbon (FA/ULisboa), R\&D Unit $n^{\circ} 4008$ and the Funding Agency for Science, Research and Technology (FCT), Portugal.

\section{References}

[1] L. Mescher, Retail Design, $1^{\text {st }}$ ed. Lausanne, Switzerland: AVA Book, 2010, p.28.

[2] K. Okakura, O Livro do Chá, $2^{\text {nd }}$ ed. Lisboa, Portugal: Cotovia/Fundação Oriente, 1998, p. 36.

[3] V. Flusser, Uma Filosofia do Design. A Forma das Coisas, $1^{\text {st }}$ ed. Lisboa, Portugal: Relógio d’Água, 2010, p. 12.

[4] A. Arendt, A Condição Humana, $1^{\text {st }}$ ed. Lisboa, Portugal: Antropos, 2001, pp. 21-73.

[5] N. Bourriaud, Estética Relacional, $2^{\text {nd }}$ ed. Córdoba, Spain: Adriana Hidalgo editora, 2008, pp. 07-22.

[6] M. Certeau, A Invenção do Quotidiano, Artes de Fazer, $3^{\text {th }}$ ed. Petrópolis, Brasil: Editora Vozes, $3^{\text {a }}$ Edição, 1998, pp. $41-42,100$.

[7] G. Lipovetsky, / J. Serroy, O Capitalismo Estético na Era da Globalização, $1^{\text {st }}$ ed. Lisboa, Portugal: Edições 70, 2014, pp. 14-17, 484-485.

[8] M. Mazzotta, Open House - A Transforming Theatre for York, Alabama , 2013. Available on Vimeo: https://vimeo.com/70386286 